\title{
HUBUNGAN OBESTTAS DENGAN CITRA DIRI DAN HARGA DIRI PADA WARGA DI DESA GAJAHWONGAN CANDEN SAMBI BOYOLAL
}

\author{
Endang Dwi Ningsih", Aan Jana ${ }^{2}$
}

\begin{abstract}
Overwight and obesity could be defined as over accumulation of the human bodyfat. Fat over accumulation could be more than $50 \%$ than total of bodyweight is consequency in seriouse patologies happened. When growing old, it is declining normally the body metabolism and cause the bodyfat storing. Personal views and attitude to effects in feeding. In every person feeding could be effected by some conditions as mood, mentally, personality, self esteem and body image, perseption in bodyshape that be affected by culture, external factors and social context in attitude towards feeding. Regarding of the background, the researcher interested to do a study the relation of the obesity with the body image and the self-esteem on the people of Gajahwongan Village Canden Sambi Boyolali. Purpose of the study to know the relation the obesity with the body image and the self- esteem on the people of Gajahwongan Village Canden Sambi Boyolali.

Subjects the 38 obesity villager of Gajahwongan Village Canden Sambi Boyolali. The sampling technique to be used is saturated sampling inwhich all of the population to be used as sample.

The result of multivariat test by double regresi logistic test showed the Negelkerke value $\mathrm{R}$ Square $34,8 \%$. Conclusion of the Research result shows that the obesity variable be affected by $34,8 \%$ variable of the body image and the self-esteem and the rest balance $65,2 \%$ variable be affected by external of research.
\end{abstract}

Keywords: Obesity, Body Image and Self-Esteem

\section{PENDAHULUAN}

Berat badan berlebih dan obesitas dapat didefinisikan sebagai akumulasi lemak tubuh secara berlebih, akumulasi lemak yang berlebihan dapat melebihi $50 \%$ berat badan total dan menyebabkan konsekuensi patologis yang berat. (Barasi, 2007) Obesitas adalah kelebihan berat badan sebagai akibat dari penimbunan lemak tubuh yang berlebihan. Jumlah lemak tubuh antara wanita dan pria tidaklah sama. Rata-rata wanita memiliki lemak tubuh yang lebih banyak dari pada pria (Hasdianah, Siyoto dan Peristyowati, 2014)

Adapun penyebab obesitas yaitu adanya pengaruh genetik dan hormon pada berat badan. Hal yang paling mendasar adalah obesitas akan terjadi jika tubuh menerima lebih banyak atau kelebihan kalori dari pada membakar kalori. Kalori tersebut kemudian akan menumpuk dan menjadi lemak. (Hasdianah, Siyoto dan Peristyowati, 2014)

Perilaku dan keyakinan
seseorang berdampak besar
terhadap makanan. Pada setiap individu, asupan makanan dapat dipengaruhi oleh: kondisi mood dan mental, kepribadian, citra diri dan harga diri, persepsi bentuk tubuh yang dipengaruhi oleh budaya, sikap terhadap makanan dalam konteks sosial dan faktor eksternal seperti pengaruh sesama anggota kelompok, iklan dan media. (Barasi, 2007) Obesitas merupakan suatu masalah yang ditakuti semua golongan usia, termasuk usia dewasa awal karena dapat 
mempengaruhi pada perubahan penampilan fisik yang tentu dapat mempengaruhi citra tubuh seseorang. (Putri, 2012)

Citra diri atau citra tubuh adalah cara individu mempersepsikan ukuran, penampilan dan fungsi tubuh serta bagian-bagiannya. Citra tubuh memiliki aspek kognitif dan afektif. Kognitif adalah pengetahuan materinya diri sendiri. Apabila citra tubuh individu mendekati ideal dirinya, individu tersebut cenderung berpikir positif tentang komponen fisik dan non fisik. Ideal tubuh sangat dipengaruhi oleh standart budaya. (Kozier, et al., 2010)

Citra tubuh adalah kumpulan sikap individu baik yang disadari maupun tidak terhadap tubuhnya, temasuk persepsi masa lalu atau sekarang mengenai ukuran, fungsi keterbatasan, makna dan obyek yang kontak secara terus-menerus. (Yusuf, Fitryasari dan Nihayati, 2015)

Harga diri adalah penilaian pribadi terhadap hasil yang dicapai dengan menganalisis seberapa banyak kesesuaian tingkah laku dengan ideal dirinya. Harga diri diperoleh dari diri sendiri dan orang lain yaitu dicintai, dihormati dan dihargai. (Suliswati, et al., 2005) Harga diri yang tinggi dapat diperoleh melalui perasaan yang berakar dalam penerimaan diri sendiri tanpa syarat, walaupun melakukan kesalahan, kekalahan dan kegagalan tetapi merasa sebagai orang yang penting dan berharga. (Murwani, 2008)

Citra diri dan harga diri merupakan komponen dari konsep diri. Konsep diri merupakan hasil dari aktivitas pengeksplorasian dan pengalamannya dengan tubuhnya sendiri. Konsep diri dipelajari melalui pengalaman pribadi setiap individu, hubungannya dengan orang lain dan interaksi dengan dunia diluarnya. (Suliswati, et al., 2005) Konsep diri yang positif memberi rasa berarti, menyeluruh dan konsisten pada seseorang. Konsep diri yang sehat memiliki derajat stabilitas yang tinggi dan menghasilkan perasaan positif terhadap diri. Komponen konsep diri terdiri atas identitas, citra diri (citra tubuh), peran, dan harga diri. ( Potter dan Perry, 2010)

Ada beberapa dampak yang ditimbulkan dari seseorang yang mengalami obesitas. Tidak hanya berdampak terhadap kesehatan mental. Dampak psikologis yang ditimbulkan seperti individu merasa malu, tidak percaya diri, dan merasa orang lain melihat beda terhadapnya. Hal tersebut dapat menyebabkan perubahan konsep diri. (Hasdianah, Siyoto dan Peristyowati, 2014) Hal yang selalu beriringan dengan obesitas adalah gangguan citra diri dan harga diri. (Kawuwung, Rompas dan Onibala, 2015)

Hubungan obesitas dengan citra diri dapat disebabkan oleh beberapa faktor yaitu keluarga, konsep diri, teman sebaya dan media massa. Pada seorang obesitas yang tumbuh pada lingkungan keluarga yang dapat memberi motivasi positif maka hal tersebut dapat mempengaruhi bagaimana cara memandang dirinya. Konsep diri yang positif berpengaruh terhadap tingkat kepuasan citra tubuhnya dan rasa puas ini dapat meningkatkan harga dirinya. (Prameswari, Aisah dan Mifbakhuddin, 2013)

Pada warga Desa Gajahwongan, dari pengamatan penulis terdapat warga dengan obesitas kurang lebih 30an orang, nampak dari pembicaraan diantara mereka merasa tidak percaya diri, malu atau merasa aktifitasnya terganggu dengan fisik yang gemuk. Beberapa warga yang gemuk berusaha menurunkan berat badan dengan diet, minum jamu, suplemen bahkan dengan cara terapi misalnya dipijat atau tusuk jarum dalam upaya untuk menguruskan badan. Selama ini 
belum pernah ada penelitian yang meneliti tentang obesitas warga tersebut yang dihubungkan dengan konsep diri yang menyangkut tentang citra diri dan harga dirinya sehingga belum dapat diketahui apakah rasa tidak percaya diri, malu dan merasa terganggu aktifitas warga tersebut berkaitan dengan berat badannya yang obesitas.

Terkait hal di atas maka penulis tertarik untuk meneliti "Hubungan antara Obesitas dengan Citra Diri dan Harga Diri pada Warga di Desa Gajahwongan Canden Sambi Boyolali".

\section{TUJUAN PENELITIAN}

1. Tujuan Umum

Untuk mengetahui hubungan obesitas dengan citra diri dan harga pada warga di Desa Gajahwongan Canden Sambi Boyolali.

2. Tujuan Khusus

a. Untuk mengetahui jumlah warga di Desa Gajahwongan Canden Sambi Boyolali yang mengalami obesitas.

b. Untuk mengetahui gambaran citra diri warga di Desa Gajahwongan Canden Sambi Boyolali.

c. Untuk mengetahui gambaran harga diri warga di Desa Gajahwongan Canden Sambi Boyolali.

d. Untuk mengetahui hubungan obesitas dengan citra diri warga di Desa Gajahwongan Canden Sambi Boyolali.

e. Untuk mengetahui hubungan obesitas dengan harga diri warga di Desa Gajahwongan Canden Sambi Boyolali.

\section{DESAIN PENELITIAN}

Desain penelitian atau disebut juga rancangan penelitian ditetapkan dengan tujuan agar penelitian dapat dilakukan dengan efektif dan efisien. Penelitian ini merupakan penelitian analitik dengan desain penelitian korelasi dan pendekatan cross sectional. Penelitian kolerasi bertujuan untuk mengungkapkan hubungan korelatif antar variabel. Sedangkan desain cross sectional merupakan rancangan penelitian yang berukuran atau pengamatannya dilakukan secara simultan pada suatu saat (sekali waktu). (Hidayat, 2008)

POPULASI, SAMPEL, DAN TEHNIK SAMPLING

Populasi dalam penelitian ini adalah warga yang obesitas di Desa Gajahwongan Canden Sambi Boyolali yang berjumlah 38 orang, sedang sampel yang digunakan adalah sebesar 38 orang. Dalam penelitian ini, peneliti menggunakan teknik sampling jenuh, dimana mengambil semua anggota populasi menjadi sampel. (Hidayat, 2008)

\section{HASIL PENELITIAN}

1. Karakteristik Responden Tabel 1.

Tabel Karakteristik Responden

\begin{tabular}{|c|c|c|c|}
\hline Karakteristik & Kategori & $\mathrm{n}$ & $\%$ \\
\hline Jenis & $\mathrm{P}$ & 23 & 61 \\
\hline Kelamin & L & 15 & 39 \\
\hline \multirow[t]{2}{*}{ Agama } & Islam & 36 & 95 \\
\hline & $\begin{array}{l}\text { Kristen/ } \\
\text { Katolik }\end{array}$ & 2 & 5 \\
\hline \multirow{2}{*}{ Usia } & $\leq 30$ & 26 & 68 \\
\hline & $>30$ & 12 & 32 \\
\hline \multirow{2}{*}{ Kegiatan } & Bekerja & 26 & 68 \\
\hline & Tidak & 12 & 32 \\
\hline \multirow{2}{*}{ Status } & Menikah & 19 & 50 \\
\hline & Belum & 19 & 50 \\
\hline \multicolumn{4}{|c|}{$\begin{array}{l}\text { Dari tabel di atas menunjukkan } \\
\text { bahwa: responden yang paling } \\
\text { banyak adalah yang berjenis } \\
\text { kelamin perempuan, beragama } \\
\text { Islam, berusia kurang atau sama } \\
\text { dengan } 30 \text { tahun, bekerja dan } \\
\text { untuk responden yang menikah } \\
\text { jumlahnya sama dengan yang } \\
\text { belum menikah. }\end{array}$} \\
\hline
\end{tabular}


2. Hasil Distribusi Variabel Obesitas, Citra Diri dan Harga Diri.

Tabel 2.

Tabel Distribusi Variabel Obesitas, Citra Diri dan Harga diri

\begin{tabular}{clcc}
\hline Variabel & Kategori & $f$ & $\%$ \\
\hline Obesitas & Pra & 26 & 68 \\
& Obesitas & & \\
& Obesitas & 12 & 32 \\
Citra Diri & Positif & 24 & 63 \\
& Negatif & 14 & 37 \\
Harga Diri & Tinggi & 19 & 50 \\
& Rendah & 19 & 50 \\
\hline
\end{tabular}

Dari tabel di atas didapatkan data bahwa: responden yang pra obesitas lebih banyak dari pada yang obesitas, yang memiliki citra diri positif lebih banyak dari pada yang memiliki citra diri negatif dan yang memiliki harga diri tinggi sama dengan yang memiliki harga diri rendah.

3. Hasil Analisis Bivariat

Tabel 3.

Tabel Hasil Analisis Bivariat

\begin{tabular}{ccccc}
\hline & & \multicolumn{3}{c}{ Obesitas } \\
\cline { 3 - 5 } Variabel & $\begin{array}{c}\text { Kate- } \\
\text { gori }\end{array}$ & $\begin{array}{c}\text { Pra } \\
\text { Obe- } \\
\text { sitas }\end{array}$ & $\begin{array}{c}\text { Obe- } \\
\text { sitas }\end{array}$ & $\mathrm{n}$ \\
\hline Citra & Pos. & 20 & 4 & 24 \\
Diri & Neg. & 6 & 8 & 14 \\
Harga & $\mathrm{T}$ & 17 & 2 & 19 \\
Diri & $\mathrm{R}$ & 9 & 10 & 19
\end{tabular}

Berdasarkan tabel di atas dapat dilihat bahwa :

a. Pada responden yang pra obesitas 20 orang memiliki citra diri positif dan 6 orang memiliki citra diri negatif, sedangkan yang obesitas 4 orang memiliki citra diri positif dan 8 orang memiliki citra diri negatif

b. Pada responden yang pra obesitas 17 orang memiliki harga diri tinggi dan 9 orang memiliki harga diri rendah, sedangkan yang obesitas 2 orang memiliki harga diri tinggi dan 10 orang memiliki harga diri rendah.
Berdasarkan hasil uji dengan menggunakan Chi Square menggunakan program SPSS for windows seri 22 dengan $\alpha=$ $5 \%(0,05)$ diperoleh hasil antara:

a. Variabel obesitas dengan citra diri diinyatakan $p$ sebesar 0,010 sehingga $p<$ 0,05 , yang berarti hipotesa diterima maka dapat ditarik kesimpulan bahwa ada hubungan antara obesitas dengan citra diri warga di Desa Gajahwongan Canden Sambi Boyolali.

b. Variabel obesitas dengan harga diri dinyatakan $p$ sebesar 0,005 sehingga $p<$ 0,05 , yang berarti hipotesa diterima maka dapat ditarik kesimpulan bahwa ada hubungan antara obesitas dengan harga diri warga di Desa Gajahwongan Canden Sambi Boyolali.

4. Hasil Analisa Multivariat Tabel 4. Hasil Analisa Multivariat

\begin{tabular}{lcc}
$\begin{array}{c}\text { Variabel } \\
\text { Independen }\end{array}$ & OR & $\mathrm{p}$ \\
\hline $\begin{array}{c}\text { Citra Diri } \\
\text { Harga DIri }\end{array}$ & 3,76 & 0,053 \\
& 6,03 & 0,116
\end{tabular}

Nagelkerke R Square 34,8\%

Berdasarkan tabel di atas menunjukkan :

a. Adanya hubungan yang positif dan signifikan antara obesitas dengan citra diri. Warga yang memiliki tubuh obesitas beresiko $3,76 \quad$ kali mengalami citra diri negatif ( $O R=3,76 ; \quad p=0,053$ )

b. Adanya hubungan yang positif dan signifikan antara obesitas dengan harga diri. Warga yang memiliki tubuh obesitas beresiko 6,03 kali mengalami harga diri rendah. $(\mathrm{OR}=6,03$; $p=0,116$ )

c. Bahwa hasil penelitian menunjukkan variabel 
independen mempengaruhi variabel dependen dapat dilihat dengan nilai Nagelkerke $\mathrm{R}$ Square $34,8 \%$ artinya bahwa variabel obesitas mempengaruhi variabel citra diri dan harga diri sebesar $34,8 \%$ dan sisanya yang $65,2 \%$ dipengaruhi oleh faktor lain.

\section{PEMBAHASAN}

1. Hubungan Obesitas dengan Citra Diri Warga.

Berdasarkan analisis univariat dapat diketahui bahwa sebagian besar tubuh warga pada kelompok pra obesitas yakni $68 \%$. Pra obesitas adalah penggolongan obesitas dengan batasan IMT tertentu sebagaimana penggolongan menurut WHO (1998) bahwa pra obesitas memiliki IMT 25 - 29,99 dan obesitas pada IMT 30 - 34,99. Jadi Pra obesitas dan obesitas menunjukkan berat badan yang berlebih. Sebagaimana yang dikemukakan oleh Hasdianah, Siyoto dan Peristyowati (2014), obesitas adalah kelebihan berat badan sebagai akibat dari penimbunan lemak tubuh yang berlebih. Adapun penyebab obesitas yaitu adanya pengaruh genetik dan hormon pada berat badan, obesitas akan terjadi jika tubuh menerima lebih banyak atau kelebihan kalori dari pada membakar kalori. Kalori tersebut kemudian akan menumpuk dan menjadi lemak.

Terkait dengan kelebihan kalori adalah tentang asupan energi warga di Desa Gajahwongan, sebagaimana yang dikemukakan oleh Barasi (2007), bahwa pengaruh eksternal terhadap asupan energi antara lain:

a. Ketersediaan, kualitas dan kuantitas makanan, banyaknya pilihan makanan baik dari kualitas maupun kuantitas menyebabkan orang mudah menemukan makanan. Hal ini sesuai informasi yang disampaikan warga Desa Gajahwongan, 100\% warga menyatakan sangat mudah mendapatkan makanan di lingkungan Desa Gajahwongan.

b. Mengudap dan mengemil, seseorang yang memiliki kebiasaan mengudap dan mengemil akan berdampak pada mekanisme pengendalian nafsu makan menjadi kurang aktif. Hal ini sesuai pernyataan warga Desa Gajahwongan bahwa $82 \%$ warga memiliki kebiasaan mengudap dan mengemil karena nafsu makannya kurang mampu dikendalikan.

c. Perilaku dan keyakinan seseorang berdampak besar terhadap asupan makanan. Sikap terhadap makanan sangat dipengaruhi oleh sesama, iklan atau media. Pandanga warga Gajahwongan menyatakan bahwa makanan yang dimakan lebih banyak pada karbohidrat dan gorengan (89\%), hal ini dipengaruhi sikap sesama kelompok warga dimana asupan kalori lebih cenderung pada kebiasaan makan yang lebih banyak menyebabkan obesitas.

Hasil analisis bivariat menunjukkan bahwa diperoleh $\mathrm{p}$ sebesar 0,010 sehingga $p<0,05$, yang berarti hipotesa diterima maka dapat ditarik kesimpulan bahwa ada hubungan antara obesitas dengan citra diri warga di Desa Gajahwongan Canden Sambi Boyolali. Sebagaimana yang dikemukakan oleh Yusuf, Fitryasari dan Nihayati (2015) bahwa citra tubuh (citra diri) 
adalah kumpulan sikap individu baik yang disadari maupun tidak terhadap tubuhnya, termasuk persepsi masa lalu atau sekarang mengenai ukuran, fungsi keterbatasan, makna dan obyek kontak secara terus menerus. Obesitas merupakan suatu masalah yang ditakuti semua golongan usia, termasuk usia dewasa awal karena dapat mempengaruhi pada perubahan penampilan fisik yang tentu mempengaruhi citra diri seseorang. (Putri, 2012)

Demikian pula penelitian yang disampaikan oleh Prameswari, Aisyah dan Mifbakhuddin (2013) bahwa hubungan obesitas dengan citra diri dapat disebabkan oleh faktor keluarga, seseorang obesitas yang tumbuh pada lingkungan keluarga yang dapat memberi motivasi positif maka hal ini dapat mempengaruhi terhadap tingkat kepuasan citra tubuhnya, terbukti bahwa warga Desa Gajahwongan baik yang pra obesitas maupun obesitas 63\% memiliki citra diri positif. Antara lain dapat dilihat pada pernyataan warga Desa Gajahwongan 79\% menyatakan bangga dengan penampilannya dan $74 \%$ menyatakan bahwa dengan penampilan tubuh yang gemuk tidak menjadi masalah penting sehari-hari, meskipun demikian $87 \%$ responden menyatakan perlu mengendalikan makanan. Hal ini sesuai dengan penelitian Nofa (2014) yang berjudul gambaran konsep diri mahasiswa yang obesitas di Fakultas Keperawatan Universitas Syiah Kuala Banda Aceh menunjukkan bahwa citra tubuh berada pada kategori positif sebesar 55,4\%.

2. Hubungan Obesitas dengan Harga Diri. Berdasarkan analisis univariat dapat diketahui bahwa responden yang memiliki harga diri tinggi $50 \%$ dan harga diri rendah $50 \%$. Tetapi dari analisis bivariat didapatkan dari 12 orang yang obesitas, 10 orang diantaranya memiliki harga diri rendah. Hal ini sesuai hasil penelitian yang disampaikan oleh Kawuwung, Rompas dan Onibala (2015) bahwa hal yang selalu beriringan dengan obesitas adalah gangguan citra diri dan harga diri. Adapun faktor predisposisi gangguan harga diri antara lain adanya penolakan dari orang lain, kurang penghargaan, persaingan atau tidak mampu mencapai standar yang ditentukan. (Suliswati, et al., 2005)

Hal demikian dikuatkan dengan hasil analisis bivariat menunjukkanl $\mathrm{p}$ sebesar 0,005 sehingga $p<0,05$, yang berarti bahwa ada hubungan antara obesitas dengan harga diri pada warga Gajahwongan. Sebagaimana yang dikutip oleh Suliswati, et al. (2005) menyatakan bahwa harga diri merupakan penilaian pribadi terhadap hasil yang dicapai dengan menganalisis seberapa banyak kesesuaian tingkah laku dengan ideal dirinya. Dan harga diri yang tinggi dapat diperoleh melalui perasaan yang berakar dalam penerimaan diri sendiri tanpa syarat walaupun melakukan kesalahan, kekalahan, dan kegagalan tetapi merasa sebagai orang yang penting dan berharga. (Murwani, 2008)

Dari analisa yang dilakukan pada responden yang obesitas menunjukkan perasaan kurang adanya penerimaan terhadap diri sendiri yang mempengaruhi rendahnya harga diri yang ditunjukkan dari pernyataan responden sebagai berikut: $97 \%$ merasa tidak percaya diri, 55\% 
sering menjadi bahan olok - olok/ bercanda, 68\% merasa minder, $61 \%$ sering bersikap negatif terhadap diri sendiri. Dan perasaan harga diri rendah juga memunculkan ketakutan akan kegagalan yaitu $76 \%$ responden menyatakan masih selalu gagal diet dan $76 \%$ menyatakan sering merasa takut sakit dengan kegemukannya.

3. Hubungan antara Obesitas dengan Citra Diri dan Harga Diri Dari analisis multivariat hasil penelitian menunjukkan variabel independen mempengaruhi variabel dependen dapat dilihat dengan nilai Nagelkerke $R$ Square $34,8 \%$ artinya bahwa variabel obesitas mempengaruhi variabel citra diri dan harga diri sebesar $34,8 \%$ dan sisanya yang $65,2 \%$ dipengaruhi variabel lain di luar penelitian. Hal ini menunjukkan bahwa pembentukan citra diri dan harga diri warga Desa Gajahwongan salah satunya dipengaruhi oleh bentuk tubuhnya yang obesitas. Sebagaimana yang dikutip oleh Suliswati, et al. (2005), bahwa citra diri dan harga diri merupakan komponen dari konsep diri, merupakan hasil dari aktivitas pengeksplorasian dan pengalamannya dengan tubuhnya sendiri. Konsep diri yang positif memberi rasa berarti, menyeluruh dan konsisten pada seseorang, konsep diri yang sehat memiliki derajat stabilitas yang tinggi dan menghasilkan perasaan positif terhadap diri sendiri.

Berdasar tabel 3, didapatkan informasi bahwa pada responden yang memiliki harga diri tinggi, yang pra obesitas lebih banyak dari pada yang obesitas, sedang pada responden yang memiliki harga diri rendah, yang pra obesitas lebih rendah dari pada yang obesitas Maka dapat diperoleh kesimpulan bahwa pada warga Desa Gajahwongan yang obesitas adanya perasaan tidak percaya diri, malu dan aktivitas terganggu. Terkait hal tersebut maka perlu diberikan penyuluhan tentang dampak dan cara mengatasi obesitas agar warga dapat meningkatkan diri mencapai tubuh yang ideal. Hal ini sesuai dengan saran yang disampaikan oleh Pramesti, Aisah dan Mifbakhuddin (2013) bahwa bagi warga yang obesitas perlu meningkatkan kemampuan fisiknya, meluangkan waktu untuk kegiatan olah raga rutin, dapat memahami perilaku apa saja yang dapat mempengaruhi kesehatan fisiknya, sehingga dapat meningkatkan citra diri dan harga diri serta memiliki pandangan yang positif terhadap tubuhnya agar terhindar dari penghinaan secara fisik. Sebagaimana yang disampaikan oleh Mustofa (2010) bahwa untuk penanganan obesitas antara lain dengan pengaturan pola makan, aktivitas fisik dan olah raga rutin dilakukan, harus mengubah perilaku penyebab kegemukan, melawan pembentukan kadar lemak dan orang tua sebaiknya waspada terhadap kebiasaan anak yang menuju obesitas.

\section{KESIMPULAN}

Dari hasil penelitian di atas dapat diperoleh kesimpulan sebagai berikut :

1. Terdapat 26 orang (68\%) pada kelompok pra obesitas dan 12 orang (32\%) pada kelompok obesitas.

2. Terdapat 24 orang (63\%) memiliki citra diri positif dan 14 orang $(37 \%)$ memiliki citra diri negatif.

3. Terdapat 19 orang (50\%) memiliki harga diri tinggi dan 19 orang $(50 \%)$ memiliki harga diri rendah. 
4. Berdasarkan hasil uji dengan menggunakan Chi Square dengan $\alpha=5 \%(0,05)$ diperoleh $p$ sebesar 0,010 sehingga $p<0,05$, yang berarti hipotesa diterima maka dapat ditarik kesimpulan bahwa ada hubungan obesitas dengan citra diri warga di Desa Gajahwongan Canden Sambi Boyolali.

5. Berdasarkan hasil uji dengan menggunakan Chi Square dengan $\alpha=5 \%(0,05)$ diperoleh $p$ sebesar 0,005 sehingga $p<0,05$, yang berarti hipotesa diterima maka dapat ditarik kesimpulan bahwa ada hubungan obesitas dengan harga diri warga di Desa Gajahwongan Canden Sambi Boyolali.

6. Dari analisa multivariat hasil penelitian menunjukkan variabel independen mempengaruhi variabel dependen dapat dilihat dengan nilai Nagelkerke $R$ Square $34,8 \%$ artinya bahwa variabel obesitas mempengaruhi variabel citra diri dan harga diri sebesar $34,8 \%$ dan sisanya yang $65,2 \%$ dipengaruhi variabel lain di luar penelitian.

\section{SARAN}

Bagi warga yang obesitas perlu meningkatkan kemampuan fisiknya, meluangkan waktu untuk kegiatan olah raga rutin, dapat memahami perilaku apa saja yang dapat mempengaruhi kesehatan fisiknya, sehingga dapat meningkatkan citra diri dan harga diri serta memiliki pandangan yang positif terhadap tubuhnya agar terhindar dari penghinaan secara fisik.

\section{DAFTAR PUSTAKA}

Barasi, M.E. 2007. At a Glance IImu Gizi. Alih bahasa Hermin Halim. Penerbit Erlangga, Jakarta.

Hasdianah, S., Suyoto dan Peristyowati, Y. 2014. Gizi : Pemanfaatan Gizi, Diet dan
Obesitas. Nuha Medika, Yogyakarta.

Hidayat, A.A.A.. 2009. Metodologi Penelitian Keperawatan dan Teknik Analisis Data. Salemba Medika, Jakarta.

Kozier, B., et al. 2010. Buku Ajar Fundamental Keperawatan : Konsep, Proses, dan Praktik. Edisi VII. Alih bahasa Pamilih Eko Karyuni. EGC, Jakarta.

Kawuwung, K.S., Rompas, S. dan Onibala, F. 2015. Hubungan Obesitas dengan Citra Tubuh dan Harga Diri Pada Remaja Putri Program Studi IImu Keperawatan Fakultas kedokteran Universitas Sam Ratulangi Manado. Jurnal Keperawatan Universitas Sam Ratulangi. Diakses 15 Juni 2016.

Murwani, A. 2008. Pengantar Konsep Dasar Keperawatan. Penerbit Fitramaya, Yogyakarta.

Mustofa, A. 2010. Solusi Ampuh Mengatasi Obesitas.Hanggar Kreator, Yogyakarta.

Nofa, I. 2014. Gambaran Konsep Diri mahasiswa yang mengalami Obesitas di Fakultas Keperawatan Universitas Syiah Kuala Banda Aceh. Jurnal Universitas Syiah Kuala Banda Aceh. Diakses tanggal 10 Juni 2011

Potter, P. dan Perry, A.G. 2005. Buku Ajar Fundamental Keperawatan Konsep, Proses, dan Praktik. Edisi V. Alih bahasa Renata Yasmin Asih. EGC, Jakarta.

Prameswari, S.P.I., Aisyah, S., dan Mifbakhuddin. 2013. Hubungan Obesitas dengan Citra Diri dan Harga Diri pada Remaja Putri di Kelurahan Jomblang Kecamatan Candisari Semarang. Jurnal Keperawatan Komunitas. 
••KOsคเn״ JIK. Vol. 4 No. 2 September 2016

Volume 1 No. 1. Diakses tanggal 2 Juni 2016.

Putri, R., 2012. Hubungan Obesitas dengan Gambaran Citra Tubuh pada Mahasiswa Fakultas IImu Pengetahuan Budaya Universitas Indonesia(FIB UI). http://library.ui.ac.id/file.file=dig ital. Diakses 10 Juni 2016

Suliswati, et al. 2005. Konsep Dasar Keperawatan Kesehatan Jiwa. EGC, Jakarta.

Yusuf, A.H., Fitryasari, R., dan Ninghayati, H.E. 2015. Buku Ajar Keperawatan Kesehatan Jiwa. Penerbit Salemba Medika, Jakarta.

${ }^{1}$ Dosen AKPER Panti Kosala Surakarta

${ }^{2}$ Mahasiswa AKPER Panti Kosala Surakarta 